\title{
O FENÔMENO DA AUSÊNCIA NA DESCONSTRUÇÃO DERRIDIANA DA PINTURA
}

\section{THE PHENOMENON OF ABSENCE ON DERRIDA'S DECONSTRUCTION OF PAINTING}

Rozângela Gontijo*

\begin{abstract}
RESUMO
Jacques Derrida foi um dos mais influentes herdeiros da fenomenologia de Husserl. Suas obras encontram adeptos em várias áreas que vão desde a filosofia, literatura até as artes em geral. Diante desse legado fenomenológico e disseminação do seu pensamento, este artigo pretende destacar, em primeiro lugar, a colisão de dois interesses fundamentais em suas obras: a crítica à metafísica da presença e o papel relevante da escrita. Na obra "La voix et le phénomène", Derrida radicaliza a fenomenologia e desestabiliza argumentos ingênuos. Num esforço de compreensão de alguns de seus quase conceitos, pretende-se, em segundo lugar, analisar a aplicação da desconstrução em alguns trechos do texto "La vérité en pointure: Restitutions", no intuito de apresentar a importância do fenômeno da ausência na desconstrução da pintura.
\end{abstract}

PALAVRAS-CHAVE: Fenomenologia. Desconstrução. Pintura. Ausência. Escrita.

\begin{abstract}
Jacques Derrida was one of the most influential heirs of Husserl's phenomenology. His works are adept in various fields ranging from philosophy, literature to the arts in general. Given this phenomenal legacy and dissemination of his thought, this article seeks to highlight, first, the collision of two fundamental interests in their works: the critique of the metaphysics of presence and role of writing. In the work "La voix et le phénomène", Derrida radicalizes phenomenology and destabilizes naive arguments. In an effort to understand some of its quasiconcepts, it is intended, secondly, to analyze the application of deconstruction in some parts of the text "La vérité en Pointure: Restitutions" in order to present the importance of the phenomenon of the absence in the deconstruction of painting.
\end{abstract}

KEYWORDS: Phenomenology. Deconstruction. Painting. Absence. Written.

\footnotetext{
* Doutoranda em Filosofia pela UFMG - email: rogontijo@hotmail.com
} 
O marco inicial de Derrida na leitura de Husserl é uma tradução comentada de $A$ origem da geometria (1961). Nessa obra ele pensava encontrar uma articulação entre ciência, fenomenologia e escrita e, por consequência, a possibilidade de uma reflexão histórica sobre a idealidade do objeto. Em entrevista televisiva com Catherine Paoletti, entre 14 e 18 de dezembro de 1998, publicadas em Sur la parole, Derrida relata esse momento decisivo na sua trajetória acadêmica:

\begin{abstract}
A lo largo de esos primeros escritos buscaba, por fidelidad a ese anhelo de escritura, lo que dentro de la fenomenología husserliana podía permitirme problematizar la escritura. ¿Dónde habla de la escritura? ¿Qué hace con ella? ¿Cómo articular esas cuestiones de la ciencia, de la fenomenología y de la escritura? Encontré ese lugar en El origen de la geometría, que, por consiguiente, empecé a interpretar en esa primera memoria a la que usted aludía, y que inmediatamente después decidí traducir (DERRIDA, 1998).
\end{abstract}

Em A voz e o fenômeno (1967) Derrida persegue essa intuição inicial, mas faz críticas às aporias de uma fenomenologia "atormentada" pela visão ingênua da metafísica da presença. Derrida procura desmembrar o conceito fenomenológico de signo, tendo em vista duas premissas investigativas: o movimento da temporalização e a intersubjetividade, pois, primeiro, na constituição da presença de um objeto temporal seria necessária uma passagem da retenção para a re-presentação (Vergegenwärtigung) que permitisse a repetição da identidade no signo. Segundo, para tornar possível uma objetividade ideal deve-se considerar a modificação da apresentação (Appräsentation) dada pelas relações intersubjetivas. (DERRIDA, 1994, p. 95).

Para Derrida o pensamento ocidental fundamentou-se em princípios de valorização da presença como verdade mediante termos como eidos, archè, telos, ousia. Tal metafísica grega e moderna adota uma lógica de pensamento fortemente baseada na filosofia do logos, carregada por oposições binárias como essência/aparência, mente/corpo, sujeito/objeto, e centrada em significados que tentam explicar a origem e os fundamentos do "ser". Desestabilizando a lógica da presença e tal hierarquia binária, ele propõe um pensamento "híbrido" que introduz um jogo de ausência e presença. A obra Gramatologia (1967) seria a grande referência de sua análise sobre as noções de origem ou de centro, no qual a filosofia até então havia se debruçado, favorecendo aquilo que se denominou a verdade do "ser" (DERRIDA, 2004, p. 13). Por meio dos exemplos de fala e escrita, Derrida demonstra que é impossível para a significação estar absolutamente presente sem fazer uso da linguagem como mediação. Se a forma sensível do significante (parole) deve permanecer como idealidade do 
significado (Bedeutung), tal idealidade depende inteiramente dos atos de repetição mediante da linguagem (DERRIDA, 1994, p. 30).

A desconstrução derridiana da fenomenologia encontra na linguagem uma posição importante. A escritura é um suplemento perigoso, mas necessário diante do fracasso da fala em proteger a presença. É preciso ter cuidado: a representação precisa entender seus limites e não tentar fazer da escrita uma presença, mas a escrita vai além: enquanto suplemento, é um excesso que enriquece culminando na presença (DERRIDA, 2004, p. 177). Derrida também considera a suplementaridade como differance, isto é, como ação de diferir. Em Margens da filosofia (1991), Derrida salienta que o verbo "diferir" pode ter dois sentidos: o mais comum (não ser idêntico, ser outro) e outro de origem latina (differe) que comporta a ação de remeter para mais tarde, de desvio, de demora e retardamento. Esse segundo sentido do verbo ligado à temporização mostra a incapacidade de se agarrar o presente vivo, assim como a "coisa mesma”. A escrita deve ser pensada considerando o efeito do diferir, logo de uma presença que difere e remete a outros elementos. Por isso, pode-se dizer que a relação entre o presente e todos os seus "foras", seja no sentido do tempo (passado e futuro) ou no sentido do espaço (o lá ao invés do aqui, o alhures), necessita de uma busca dos rastros que possibilitem a significação:

\begin{abstract}
A diferença é o que faz com que o movimento da significação não seja possível a não ser que cada elemento dito "presente" que aparece sobre a cena da presença, se relacione com outra coisa que não ele mesmo, guardando em si a marca do elemento passado e deixando-se moldar pela marca da sua relação com o elemento futuro, relacionando-se o rastro menos com aquilo a que se chama presente do que àquilo a que se chama passado, e constituindo aquilo a que chamamos presente por intermédio dessa relação mesma com o que não é ele mesmo próprio: absolutamente não ele próprio, nem mesmo um passado ou um futuro como presentes modificados. (DERRIDA, 1991, p. 45).
\end{abstract}

Analisando essa citação, é possível compreender três pontos fundamentais na desconstrução derridiana da metafísica da presença: a) a aporia da presença, logo a ingenuidade da metafísica da presença, b) a inevitável contaminação da presença pelo outro, logo a necessidade de se considerar a alteridade ou intersubjetividade na significação e c) a noção de "rastro" e sua alteridade irredutível, de um significar sem aparecer. Portanto, a desconstrução olha com ironia para as determinações de verdade da metafísica da presença. Para Derrida, se essa ilusão é fruto das oposições metafísicas e do louvor ao logocentrismo, a escrita quebra com esse paradigma no jogo entre ausência e presença na significação. A escrita é a ausência que aparece, o silêncio que fala, a contaminação pelo desvio. Através da 
escrita, Derrida (1994, p.29) favorece a "face sensível do signo", ou seja, o signo expressivo como toda a sua evidente contaminação, mas é preciso notar que na escrita há um aparente paradoxo: ela é, ao mesmo tempo, a possibilidade de significação e a morte do presente vivo. Essa aporia pode ser explicitada em A farmácia de Platão (1968):

SÓCRATES: - O uso da escrita, Fedro, tem um inconveniente que se assemelha à pintura. Também as figuras pintadas têm a atitude de pessoas vivas, mas se alguém as interrogar conservar-se-ão gravemente caladas. O mesmo sucede com os discursos. Falam de coisas como se as conhecessem, mas quando alguém quer informar-se sobre qualquer ponto do assunto exposto, eles se limitam a repetir sempre a mesma coisa. Uma vez escrito, um discurso sai a vagar por toda parte, não só entre os conhecedores, mas também entre os que o não entende e nunca se pode dizer para quem serve e para quem não serve. Quando é desprezado ou injustamente censurado, necessita o auxílio do pai, pois não é capaz de defender-se nem de se proteger por si. (PLATÃO, Fedro).

Para Derrida o pharmakon apresenta o "inconveniente" da escrita (ou da representação). Compreende que no Fedro a escritura se limita a repetir, mas, por isso mesmo, é o melhor e mais nobre dos jogos. A pergunta de Derrida: "Quais são, em profundidade, sob os enunciados de Sócrates, os traços de semelhança que fazem da escritura um homólogo da pintura?" (DERRIDA, 2005, p. 87). No Fedro a ordem escritural é a imagem da fala ou a voz em elementos abstratos, enquanto a pintura é a imagem representativa que produz uma aparência ou o fantasma que já simula a cópia.

A partir dessa breve introdução sobre a herança fenomenológica na desconstrução, e dessa inspiração da analogia entre escrita e pintura no Fedro, passo à introdução de alguns pontos do texto La verité en pointure: restitutions (1978). Esse texto tem como referência o ensaio de Meyer Schapiro "The Still Life as a Personal Object” (1968) e sua crítica sobre o que Heidegger diz dos sapatos de Van Gogh na obra "A origem da obra de arte" (1935-36). Schapiro acusa Heidegger de projetar um "pathos" sobre a obra, como uma espécie de slide de atribuição dos sapatos ao camponês, e nada na pintura evidencia tais afirmações. Heidegger também é acusado de ser fantasioso e subjetivo, ou até mesmo de possuir uma subjetividade nazista, ao pregar a volta aos campos. Para Schapiro os sapatos da pintura seriam do próprio Van Gogh, uma espécie de "autorretrato" de Vincent. Portanto, o filósofo teria cometido o grave erro de perder a presença do artista na obra. (DERRIDA, 1978, p.355).

Segundo Derrida, se há verdade como atribuição em Heidegger, Schapiro também comete o mesmo erro ao considerar os sapatos como propriedade do pintor. Em defesa de Heidegger, Derrida desconstrói teses tradicionais da verdade como adequação ou atribuição: 
mesmo em Heidegger não há uma "verdade camponesa", pois as características do campo são secundárias, sendo que a "verdade mesma poderia ser apresentada por qualquer quadro de sapatos ou até mesmo qualquer produto em geral. Heidegger não amarra os sapatos a um portador. O pertencimento dos produtos "sapatos" não se refere a um determinado sujeito, ou até mesmo a um determinado mundo. (DERRIDA, 1978, p. 356).

Para Derrida, nessa querela existe ao mesmo tempo uma simetria e uma dissimetria: do lado de Heidegger há uma verdade como presença revelada e do lado de Schapiro uma verdade como adequação de uma representação. A epígrafe de Cézanne que abre o texto: "Devo-lhe a verdade na pintura e vou dizer isso a você" (DERRIDA, 1978, p. 291) faz uma promessa; então indagamos: como dizer a verdade na pintura? Para Derrida, não é possível restituir a coisa, mas mesmo assim, é preciso que se pense sobre ela. Como veremos, há um caminho para uma restituição dos sapatos, do quadro, enfim da pintura como verdade. É o caminho da procura dos "rastros" ou os vestígios, como em uma investigação policial.

Nessa espécie de processo investigativo ou de um colóquio de pensadores, várias vozes entram em cena, que vão desde Schapiro (historiador de arte) e sua correspondência com Heidegger até os fantasmas, como é o caso do homenageado de Schapiro Kurt Goldstein (neurologista psiquiatra) e com ele outros mais conhecidos como Van Gogh, Artaud, Freud e Marx. Diante de todos esses participantes vivos ou mortos, o anacronismo do polilóquio mantém a tônica da desconstrução espectral da filosofia de Derrida.

Segundo Serra:

\footnotetext{
Ao espectro ou fantasma é inerente um antagonismo da imagem enquanto visibilidade de uma presença que não se vê diretamente, mas que está lá, circundando o fenômeno, naquilo que, a partir do visível, imagina-se, projeta-se, segundo o que nele se quer ver (SERRA, 2011, p. 126).
}

Derrida traduz bem a importância da espectrologia na fenomenologia, assim como na escrita e na pintura. Portanto, ele abre o polilóquio com uma questão, dando a entender que a discussão já estava acontecendo: há fantasmas nos quadros de Van Gogh? Os fantasmas, como já dito no Fedro, estão presentes na pintura, mas no polilóquio de Derrida, mais do que presentes, eles são os ausentes que disseminam os sujets (entendidos como sujeitos e temas) mostrando que é impossível enlaçá-los ou delimitá-los com segurança. Existe assim uma abertura e desmoronamento nos laços frouxos ou desenlaçados dos sapatos, que ultrapassam os limites do quadro. 
O parergon (o fora da obra) merece relevância em Derrida por este considerar aquilo que antes fora renegado pela tradição filosófica, aquilo que antes estava como suplemento ou hierarquicamente secundário, trazendo esses elementos como essenciais. Assim como na escrita, o parergon do quadro também é uma lógica do suplemento e, da mesma forma, também se torna a própria manifestação do fenômeno da ausência. A estrutura parergonal interessa a Derrida por mostrar que algo "fora da obra" pode ser atribuído ao "dentro da obra" (DERRIDA, 1978, p. 344-345). Há uma contaminação irredutível da alteridade.

A ideia do polilóquio também traduz um pensamento contaminado e atravessado pelo outro, e a "noção" de rastro abre o pensamento a uma alteridade irredutível. Derrida mostra que não há fundo e, mesmo que ele existisse, seria impossível alcançá-lo sem a diferença ou sem uma interpretação contaminada. Não há pureza do ser, se já estamos emaranhados em uma teia de pré-conceitos. A questão: "O que está presente nos quadros de Van Gogh? Em uma carta de Vincent Van Gogh a Theo, o pintor narra ao seu irmão a aparição de uma mariposa noturna em seu quarto. Van Gogh se recusa a pintá-la. Na recusa, há a questão: "para pintá-la teria que matá-la". A natureza morta ou "The still life" do quadro como, diria Schapiro, é a presença de uma ausência. Para a fenomenologia de Husserl a fantasia é a presentificação de uma ausência. Para Derrida, ausência e presença são estados fundamentais do ser do fenômeno. E é isso que ele dialoga ou joga para mostrar no quadro de Van Gogh: a desconstrução da verdade enquanto presença, adequação ou representação na obra de arte.

Se há fantasmas no quadro, eles devem estar em pares. Schapiro e Heidegger concordam que são pares de sapatos. Para Derrida essa é uma afirmação apressada, talvez por assim ser melhor o emparelhar dos pares: de sapatos, de correspondência, de pensadores, de gêneros sexuais. Mediante o quadro "Os pares de sapatos de camponês", Derrida irá desconstruir os pares (ou oposições binárias), ainda na investigação de uma possível verdade prometida por Cézanne.

Derrida ironiza ambos quanto à certeza de se tratar de um par: "E quanto mais olho para eles, mais eles me olham, menos eles se parecem com um velho par. Melhor, um velho casal. É a mesma coisa?" (DERRIDA, 1978, p. 317). Afinal o "des-parear" também pode afetar a disposição de "verdade", quando nos conduzimos pelo simbolismo da bissexualidade. Ao analisar o quadro, Derrida nota que o par de sapatos está desenlaçado, indicando que eles não se pertencem nem pertencem a nenhum lugar, mas estão lá desligados e frouxos, feitos apenas para "restar" (DERRIDA, 1978, p. 312). A restância na obra dá-se por essa separação de sua origem, mas que mantém uma marca, isto é, os sapatos e seus cadarços um pouco 
desfeitos fazem o re-marcar da pintura. (DERRIDA, 1978, p. 391). Derrida faz uma análise espectral da separação interna de um sapato para dizer que toda essa investigação acerca da verdade dos sapatos não se baseia em nada a não ser em restos e rastros em um solo sem fundo (DERRIDA, 1978, p. 415). Entende assim o "rastro" como possibilidade de uma abertura para o exterior e a verdade como "diferencia".

Assim como houve uma pressa em constatar, sem a menor dúvida, que se tratava de um par (um direito e outro esquerdo) também houve uma ingenuidade inacreditável por parte do especialista Schapiro, ao identificar a pintura nos moldes de uma arte representativa imitativa, no sentido mais simples de uma "cópia” (DERRIDA, 1978, p. 318). Parece que, ao interpretar um quadro, existe o risco de cairmos em uma armadilha, e Derrida chama atenção para um detalhe: na série de quadros de sapatos há um deles cujo laço parece fazer um emaranhado estranho, uma espécie de armadilha, um laço semiaberto (DERRIDA, 1978, p. 316). Para Derrida a armadilha foi que ambos se precipitaram em preencher com o seu nome ou o nome de uma sociedade o pertencimento do quadro como um cheque ao portador: Heidegger para uma sociedade agrícola, da terra, rural, sedentário; Schapiro para uma sociedade industrial, da cidade, nômade ou emigrante (DERRIDA, 1978, p. 320).

Longe de querer resolver esta querela, Derrida pretende pensar sobre ela, sobre os quadros, sobre a pintura. Se o "famoso quadro" inicialmente foi pensado como restituição, no polilóquio não só os sapatos da série de Van Gogh, mas muitos outros quadros também são apresentados, havendo assim um labirinto de inscrições de imagens e vozes. Em $A$ voz e o fenômeno, através da obra do jovem David Téniers vemos uma galeria com corredores e muitos quadros, alguns "dependurados" ao alto, outros abaixo ou mesmo no chão. Nosso olhar perde-se em uma proliferação de signos e não podemos permanecer em lugar algum. Para Derrida essa galeria não aparece como um caso particular da experiência, como pensaria Husserl, mas o fenômeno ali é o próprio labirinto, que não deixa nosso olhar se fixar em algo. Derrida diz: só nos resta falar e fazer ressoar nossa voz nas paredes, a voz que ressoa de nós é o próprio fenômeno, como fantasmas que se apresentam na ausência (DERRIDA, 1994, p. 117). Também em La vérité em pointure: restitutions, a querela entre Heidegger e Schapiro, não só os sapatos de Van Gogh, mas muitos outros quadros que apresentam sapatos se inscrevem em um entrelaçamento de vozes, mostrando que o sentido não está nos sapatos pintados, mas em uma voz silenciosa que parte da própria obra.

A chave de investigação de Derrida é o fantasma como idealidade de sentido. Em Espectros de Marx, o fantasma de Hamlet aparece para dizer a verdade, mas ele de início não 
fala, ele fica mudo. Ele também é uma "aparição" já que não está vivo, mas também não está morto. Sendo algo indefinível, inapresentável, Derrida estabelece o fantasma no terreno do indecidível e, portanto, sua espectrologia radicaliza a fenomenologia de Husserl, ao mostrar que a fenomenologia é muito mais que uma filosofia que se dedica ao "aparecer" de um presente vivo. O ser do fenômeno pode ser uma ausência que indica presença, uma morte que indica vida ou uma representação que indica realidade. A inexistência, a irrealidade e os espectros são fenômenos que reivindicam o estatuto fenomenológico do "aparecer". Em uma relação entre fenomenologia da existência e uma semiologia do inexistente o suplemento, assim como o rastro permitem uma verdade da diferencia. Assim conclui Derrida em $A$ voz $e$ ofenômeno:

\begin{abstract}
A história da metafísica é o querer-ouvir-se-falar absoluto. Essa história está fechada quando esse absoluto infinito aparece a si como sua própria morte. Uma voz sem diferencia, uma voz sem escritura é, a um só tempo, absolutamente viva e absolutamente morta (DERRIDA, 1994, p. 116).
\end{abstract}

\title{
Referências
}

DERRIDA, Jacques. A voz e o fenômeno: introdução ao problema do signo na fenomenologia de Husserl. Trad. Lucy Magalhães. Rio de Janeiro: Jorge Zahar Editor, 1994.

DERRIDA, Jacques. Margens da filosofia. Trad. Joaquim Costa, António M. Magalhães. Campinas, SP: Papirus, 1991.

DERRIDA, Jacques. De la verité en peinture. Paris: Flammarion, 1978.

DERRIDA, Jacques. Introdução e tradução. In: HUSSERL, Edmund. L'origine de la géométrie. Paris: PUF, 1962.

DERRIDA, Jacques. Spectres de Marx. L'État de la dette, le travail du deuil et La nouvelle internationale. Paris: Galilée, 1993.

DERRIDA, Jacques. A farmácia de Platão. Trad. Rogério Costa. São Paulo: Iluminuras, 2005.

DERRIDA, Jacques. Gramatologia. Trad. Miriam Chnaiderman e Renato Janine Ribeiro. São Paulo: Perspectiva, 2004.

HUSSERL, Edmund. Investigações lógicas. Trad. Zeljko Loparic, São Paulo, 1975. (Coleção Os Pensadores). 
HEIDEGGER, Martin. A origem da obra de arte. Trad. Maria da Conceição Costa, Edições 70, Lisboa, Portugal, 1977.

PLATÃO. Fedro. São Paulo: Martin Claret, 2011).

SCHAPIRO, Meyer. The still life as a personal object - Note on Heidegger and Van Gogh. Mácula, 1968.

SERRA, Alice. A restância do traço e a desconstrução da origem na estética quasetranscendental de Jacques Derrida. Arte filosofia, Ouro Preto, No. 10, p.120-134, 2011. 